\title{
Oxidative 3,3,3-trifluoropropylation of arylaldehydes
}

\author{
Akari Ikeda, Masaaki Omote, Shiho Nomura, Miyuu Tanaka, Atsushi Tarui, \\ Kazuyuki Sato and Akira Ando*
}

\author{
Full Research Paper \\ Address: \\ Faculty of Pharmaceutical Sciences, Setsunan University, 45-1, \\ Nagaotoge-cho, Hirakata, Osaka 573-0101, Japan \\ Email: \\ Akira Ando* - aando@pharm.setsunan.ac.jp \\ * Corresponding author \\ Keywords: \\ cesium fluoride; organo-fluorine; 1,3-proton shift; trifluoromethyl; \\ 3,3,3-trifluoropropenyl
}

Open Access

Beilstein J. Org. Chem. 2013, 9, 2417-2421.

doi:10.3762/bjoc. 9.279

Received: 27 August 2013

Accepted: 10 October 2013

Published: 11 November 2013

This article is part of the Thematic Series "Organo-fluorine chemistry III".

Guest Editor: D. O'Hagan

(C) 2013 Ikeda et al; licensee Beilstein-Institut.

License and terms: see end of document.

\begin{abstract}
A reaction between $(E)$-trimethyl(3,3,3-trifluoroprop-1-en-1-yl)silane (1) and arylaldehydes 2 was triggered by fluoride anions to afford aryl 3,3,3-trifluoropropyl ketones 3 in moderate to good yield. A mechanistic study of this reaction indicated that it occurred via an allyl alkoxide (4). A subsequent 1,3-proton shift of the benzylic proton of $\mathbf{4}$ forms $\mathbf{3}$. This reaction involves oxidative 3,3,3trifluoropropylation of an arylaldehyde to afford 4,4,4-trifluoro-1-arylbutan-1-one.
\end{abstract}

\section{Introduction}

Trifluoromethyl groups are an essential motif in pharmaceuticals, agricultural chemicals, and functional materials because trifluoromethylation of such chemicals often significantly improves their performance [1-6]. To date, the trifluoromethylation of carbonyl compounds [7-10] and aryl halides [11-13] has been extensively explored. On the other hand, the 2,2,2-trifluoroethylation and the 3,3,3-trifluoropropylation, which elongate the product by two and three carbon atoms, respectively, have not been explored yet. 2-Bromo-3,3,3-trifluoropropene [14-26] and 1,1,1,3,3-pentafluoropropane [27,28] have been used in place of (3,3,3-trifluoropropynyl)lithium, which can add to carbonyl compounds and couple with aryl halides through a zinc intermediate. For the 3,3,3-trifluoropropenyl synthon Yamazaki et al. reported the use of 2-(trifluoromethyl)-1-(phenyl- sulfenyl)vinyltrimethylsilane for the addition to aldehydes in the presence of fluoride anion [29]. Recently, Prakash et al. [30] reported the synthesis of $\beta$-trifluoromethylstyrenes through a Heck coupling reaction of aryl iodides with 1-iodo-3,3,3-trifluoropropane, allowing a direct introduction of 3,3,3-trifluoropropenyl groups to aromatic rings. Approximately at the same time, our research group demonstrated that $(E)$-trimethyl(3,3,3trifluoroprop-1-en-1-yl)silane (1) effectively participated in a Hiyama cross-coupling reaction with aryl iodide to construct $\beta$-trifluoromethylstyrenes in good to excellent yield [31,32]. In the course of this study, we found that the reaction of $\mathbf{1}$ with benzaldehyde in the presence of fluoride anions afforded an allyl alcohol, which spontaneously isomerized to phenyl 3,3,3trifluoropropyl ketone (3a). This reaction involves a one-pot 
synthesis of aryl 3,3,3-trifluoropropyl ketones from the corresponding arylaldehyde, representing the oxidative 3,3,3-propenylation of the arylaldehyde. Here, we report our study of this unusual reaction.

\section{Results and Discussion}

At the outset of our study, we attempted selective $\mathrm{C}-\mathrm{Si}$ bond dissociation of 1 with several fluoride anion sources. The subsequently generated carbanion was trapped with benzaldehyde to generate 4,4,4-trifluoromethylallyl alcohol 4 (Table 1). We found that this reaction did not take place when either $\mathrm{TiF}_{4}$ in THF or $\mathrm{CuF}_{2}$ /dppp in DMF was used (Table 1, entries 1 and 2). However, the reaction proceeded when two equivalents of $\mathrm{CsF}$ to arylaldehyde $\mathbf{2}$ were used in DMA at a temperature of $55^{\circ} \mathrm{C}$, affording $\mathbf{3 a}$ and $\mathbf{4 a}$ in $15 \%$ and $16 \%$ yield, respectively (Table 1 , entry 3 ). In contrast, the reaction did not proceed in THF (Table 1, entry 4). The yield increased as the temperature was raised to $80^{\circ} \mathrm{C}$, but a further increase to $100^{\circ} \mathrm{C}$ did not improve the yield of the reaction (Table 1, entries 5 and 6). Changing the solvent to DMF considerably shortened the reaction time. The added amount of CsF also influenced this reaction. The reaction conducted with four equivalents of $\mathrm{CsF}$ afforded $3 \mathbf{a}$ and $4 \mathbf{a}$ in $52 \%$ and $27 \%$ yield, respectively (Table 1, entry 8). However, a further increase of the amount of $\mathrm{CsF}$ did not improve the reaction yield (Table 1, entry 9). We thus determined that the conditions used in entry 8 of Table 1 were optimal. We explored the scope and limitation of this reaction by using these optimal conditions.
A variety of arylaldehydes participated in the reaction to give products in moderate to good yields (Table 2). The reactions with benzaldehyde derivatives with an electron-withdrawing group, such as chloro-, bromo-, fluoro- or trifluoromethyl, at the para-position proceeded to give $\mathbf{3} \mathbf{b}-\mathbf{e}$ in moderate to good yields (Table 2, entries 1 to 4). The substitution with other electron-withdrawing groups such as methoxycarbonyl and cyano decreased the yield of the product, $\mathbf{3 f}$ and $\mathbf{3} \mathbf{g}$ were obtained in $38 \%$ and $46 \%$ yield, respectively (Table 2 , entries 5 and 6 ). In contrast, the substitution of benzaldehyde with an electrondonating group slowed down the reaction substantially. $p$-Methyl and $p$-methoxybenzaldehydes gave $\mathbf{3 h}$ and $\mathbf{3 i}$ in $26 \%$ and $17 \%$ yield, respectively (Table 2 , entries 7 and 8 ). metaSubstitution of benzaldehyde with a methoxy group gave $\mathbf{3} \mathbf{j}$ in $58 \%$ yield (Table 2, entry 9). These results are in accordance with the Hammett equation. ortho-Substitution of substrates decreased the yield of the products substantially, probably because of the steric hindrance introduced by the substituent (Table 2, entries 10 and 11). While the reaction could be applied to polycyclic and heterocyclic compounds, $\mathbf{3 m}$ and $\mathbf{3 n}$ were only obtained in low yield (Table 2, entries 12 and 13). An aliphatic aldehyde did not participate in the reaction (Table 2, entry 14).

During the course of this study, it became obvious that the reaction gave allyl alcohol 4 first, and then subsequent transformation of $\mathbf{4}$ into $\mathbf{3}$ occurred during the reaction process. Recently, both Cahard et al. [33,34] and Qing et al. [35] independently

Table 1: Reaction of 1 with benzaldehyde in the presence of fluoride anions. ${ }^{a}$

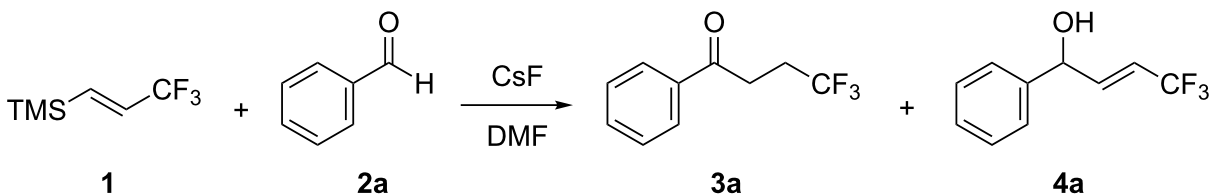

\begin{tabular}{|c|c|c|c|c|c|c|c|}
\hline \multirow[t]{2}{*}{ entry } & \multirow[t]{2}{*}{$\mathrm{F}$ anion (equiv) ${ }^{\mathrm{b}}$} & \multirow[t]{2}{*}{1 (equiv) $^{b}$} & \multirow[t]{2}{*}{ solvent } & \multirow[t]{2}{*}{ temp $\left({ }^{\circ} \mathrm{C}\right)$} & \multirow[t]{2}{*}{ time $(\mathrm{h})$} & \multicolumn{2}{|c|}{ yield $(\%)^{c, d}$} \\
\hline & & & & & & $3 \mathbf{a}$ & $4 a$ \\
\hline 1 & $\mathrm{TiF}_{4}(2)$ & 2 & THF & 60 & 24 & - & - \\
\hline 2 & $\mathrm{CuF}_{2}(1) / \mathrm{dppp}(2)$ & 2 & DMF & 80 & 26 & - & - \\
\hline 3 & $\operatorname{CsF}(2)$ & 1.5 & DMA & 55 & 24 & 15 & 16 \\
\hline 4 & $\operatorname{CsF}(2)$ & 1.5 & THF & 55 & 24 & - & - \\
\hline 5 & $\operatorname{CsF}(2)$ & 2 & DMA & 80 & 4 & 53 & - \\
\hline 6 & $\operatorname{CsF}(2)$ & 2 & DMA & 100 & 4 & 47 & - \\
\hline 7 & $\operatorname{CsF}(2)$ & 2 & DMF & 80 & 1 & 49 & 10 \\
\hline 8 & $\operatorname{CsF}(4)$ & 2 & DMF & 80 & 1 & $52(43)$ & 27 \\
\hline 9 & $\operatorname{CsF}(6)$ & 2 & DMF & 80 & 1 & 38 & 5 \\
\hline
\end{tabular}

${ }^{a}$ The reaction was carried out with $2 \mathrm{a}(0.2 \mathrm{mmol})$ and a solvent $(2.0 \mathrm{~mL}) .{ }^{\mathrm{b}}$ The value in parentheses indicates equiv with respect to benzaldehyde $(0.2$ $\mathrm{mmol}$ ). ${ }^{\mathrm{C}} \mathrm{NMR}$ yields, which were calculated by integration of the ${ }^{19} \mathrm{~F}$ NMR signals of $\mathbf{3 a}$ and $4 \mathbf{a}$ relative to that of the internal standard of 1,4 -bis(trifluoromethyl)benzene. ${ }^{\mathrm{d}}$ The value in parentheses indicates isolated yield (\%). 


\begin{tabular}{|c|c|c|c|c|c|}
\hline entry & $\mathrm{Ar}-\mathrm{CHO}$ & 3 & yield $(\%)^{b}$ & 4 & yield $(\%)^{b}$ \\
\hline 1 & $p-\mathrm{Cl}-\mathrm{C}_{6} \mathrm{H}_{4}$ & $3 b$ & 72 & $4 b$ & 8 \\
\hline 2 & $p-\mathrm{Br}-\mathrm{C}_{6} \mathrm{H}_{4}$ & $3 c$ & 79 & $4 c$ & 6 \\
\hline 3 & $p-\mathrm{F}-\mathrm{C}_{6} \mathrm{H}_{4}$ & $3 d$ & 55 & 4d & 4 \\
\hline 4 & $p-\mathrm{CF}_{3}-\mathrm{C}_{6} \mathrm{H}_{4}$ & $3 e$ & 59 & $4 e$ & 6 \\
\hline 5 & $p-\mathrm{CH}_{3} \mathrm{OC}(\mathrm{O})-\mathrm{C}_{6} \mathrm{H}_{4}$ & $3 f$ & 38 & $4 f$ & 6 \\
\hline 6 & $p-\mathrm{CN}-\mathrm{C}_{6} \mathrm{H}_{4}$ & $3 \mathbf{g}$ & 46 & $\mathbf{4 g}$ & 10 \\
\hline 7 & $p-\mathrm{CH}_{3}-\mathrm{C}_{6} \mathrm{H}_{4}$ & $3 h$ & 26 & $4 h$ & 8 \\
\hline 8 & $p-\mathrm{CH}_{3} \mathrm{O}-\mathrm{C}_{6} \mathrm{H}_{4}$ & $3 \mathbf{i}$ & 17 & $4 \mathbf{i}$ & 16 \\
\hline 9 & $m-\mathrm{CH}_{3} \mathrm{O}-\mathrm{C}_{6} \mathrm{H}_{4}$ & $3 \mathbf{j}$ & 58 & $4 \mathbf{j}$ & 10 \\
\hline 10 & $\mathrm{o}-\mathrm{CH}_{3} \mathrm{O}-\mathrm{C}_{6} \mathrm{H}_{4}$ & $3 k$ & 12 & $\mathbf{4 k}$ & 35 \\
\hline 11 & $\mathrm{o}-\mathrm{Cl}-\mathrm{C}_{6} \mathrm{H}_{4}$ & 31 & 16 & 41 & 16 \\
\hline 12 & 2-naphthyl & $3 m$ & 41 & $4 m$ & 5 \\
\hline 13 & 3-pyridyl & $3 n$ & 31 & $4 n$ & 12 \\
\hline 14 & $\mathrm{C}_{6} \mathrm{H}_{5}\left(\mathrm{CH}_{2}\right)_{2}$ & 30 & - & 30 & - \\
\hline
\end{tabular}

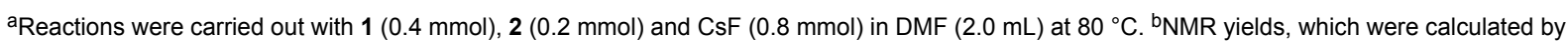
integration of the ${ }^{19} \mathrm{~F}$ NMR signals 3 and 4 relative to that of the internal standard of 1,4-bis(trifluoromethyl)benzene.

reported that the isomerization of a 4,4,4-trifluoromethylallyl alcohol substructure was promoted by a ruthenium catalyst to form a 3,3,3-trifluoropropylcarbonyl unit. We hypothesized that the formation of $\mathbf{3}$ would be promoted by inter- or intramolecular migration of the benzylic proton of $\mathbf{4}$ in the basic medium. To confirm the hypothesis, we conducted the reaction by using benzaldehyde- $d$ to clarify whether or not proton migration was involved in the reaction sequence. When benzaldehyde- $d$ was treated with 1 and $\mathrm{CsF}$ in $\mathrm{DMF}$ at $80^{\circ} \mathrm{C}$, the reaction gave a product in which deuterium was inserted on the $\alpha$ - and $\beta$-carbons of the carbonyl group with rates of $22 \%$ and $53 \%$, respectively (Scheme 1, (1)). This result suggests that deuterium on the $\beta$-carbon should be incorporated by a 1,3 -proton shift. In contrast, deuterium on the $\alpha$-carbon should be inserted when the enolate intermediate, which is generated during the reaction, intermolecularly extracted the benzylic deuterium of 4 . To further investigate the reaction mechanism, 4a was exposed to basic conditions to observe whether or not the isomerization of 4a to 3a would occur. Indeed, the treatment of $4 \mathbf{a}$ with a stoichiometric amount of DBU resulted in an almost quantitative conversion to $\mathbf{3 a}$ (Scheme 1, (2)).

This suggests that the reaction provides 4 first. 4 subsequently isomerizes to form 3, which is an oxidative 3,3,3-trifluoropropylation of the arylaldehyde. These results allowed us to propose the reaction mechanism shown in Scheme 2, which includes the isomerization of $\mathbf{5}$ to $\mathbf{6}$ in the formation of $\mathbf{3}$. To support our proposed mechanism, a computational calculation was performed with Gaussian $03 \mathrm{~W}$ at the B3LYP/6-31+G* level of theory to confirm that key intermediate 7 was involved in the isomerization process. The calculation indicated that intermediate $\mathbf{5}$ generated in the first step of the reaction was

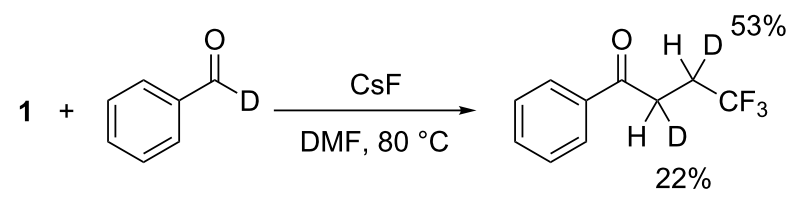<smiles>COc1ccc(C(O)/C=C/C(F)(F)F)cc1</smiles> 


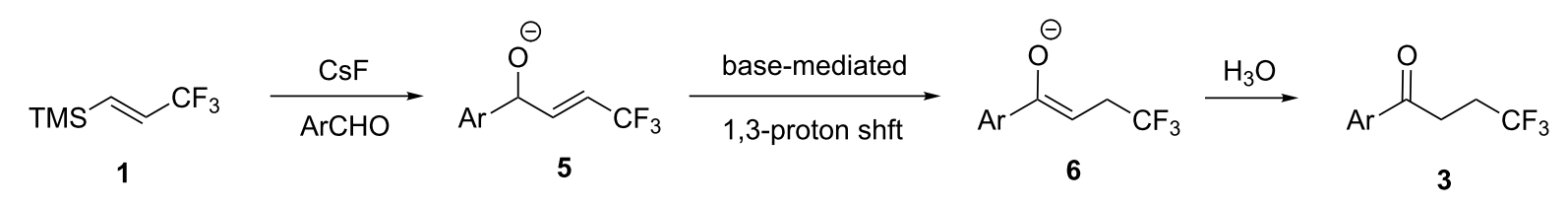

$$
\begin{aligned}
& {\left[\mathrm{Ar}_{\mathrm{\Theta}}^{\mathrm{OH}} \mathrm{CF}_{3}\right]} \\
& 7
\end{aligned}
$$

Scheme 2: The proposed reaction mechanism.

slightly more stable $(0.417 \mathrm{kcal} / \mathrm{mol})$ than 7 . The slight energy difference between 5 and 7 indicates the viability of 7 in the reaction medium. The generation of 7 would facilitate the isomerization of $\mathbf{5}$ to $\mathbf{6}$.

\section{Conclusion}

We reacted 1 with benzaldehyde in the presence of CsF to provide $\mathbf{3}$. We demonstrated that $\mathbf{4}$ was generated in the first step of the reaction, and then subsequently isomerized to $\mathbf{3}$ under basic conditions. This sequential reaction involves an oxidative 3,3,3-trifluoropropylation of the arylaldehyde to form a 3,3,3-trifluoropropylcarbonyl unit. A further refinement of the reaction conditions to enhance the compatibility of the reaction with substrates such as aliphatic aldehydes is in progress in our group.

\section{Supporting Information}

\section{Supporting Information File 1}

Experimental details and characterization data for all new compounds.

[http://www.beilstein-journals.org/bjoc/content/ supplementary/1860-5397-9-279-S1.pdf]

\section{Acknowledgements}

We thank Professor Takashi Yamazaki from the Graduate School of Engineering, Tokyo University of Agriculture and Technology for calculating the molecular stability of $\mathbf{5}$ and $\mathbf{7}$.

\section{References}

1. Tomaschenko, O. A.; Grushin, V. V. Chem. Rev. 2011, 111, 4475-4521. doi:10.1021/cr1004293

2. Yamazaki, T.; Taguchi, T.; Ojima, I. Unique Properties of Fluorine and Their Relevance to Medicinal Chemistry and Chemical Biology. In Fluorine in Medicinal Chemistry and Chemical Biology; Ojima, I., Ed.; Wiley-Blackwell: Chichester, U.K., 2009; pp 3-46.

3. Purser, S.; Moore, P. R.; Swallow, S.; Gouverneur, V. Chem. Soc. Rev. 2008, 37, 320-330. doi:10.1039/b610213c
4. Müller, K.; Faeh, C.; Diederich, F. Science 2007, 317, 1881-1886. doi:10.1126/science.1131943

5. Kirsch, P. Modern Fluoroorganic Chemistry: Synthesis, Reactivity, Applications; Wiley-VCH: Weinheim, Germany, 2004. doi:10.1002/352760393X

6. Hiyama, T. In Organofluorine Chemistry, Principles, and Commercial Applications; Banks, R. E.; Smart, B. E.; Tatlow, C. J., Eds.; Springer: New York, 1994; pp 237-262.

7. Prakash, G. K. S.; Yudin, A. K. Chem. Rev. 1997, 97, 757-786. doi:10.1021/cr9408991

8. Prakash, G. K. S.; Krishnamurti, R.; Olah, G. A. J. Am. Chem. Soc. 1989, 111, 393-395. doi:10.1021/ja00183a073

9. Shibata, N.; Mizuta, S.; Kawai, H. Tetrahedron: Asymmetry 2008, 19, 2633-2644. doi:10.1016/j.tetasy.2008.11.011

10. Ma, J.-A.; Cahard, D. J. Fluorine Chem. 2007, 128, 975-996. doi:10.1016/j.jluchem.2007.04.026

11. Kobayashi, Y.; Kumadaki, I. Tetrahedron Lett. 1969, 10, 4095-4096. doi:10.1016/S0040-4039(01)88624-X

12. Oishi, M.; Kondo, H.; Amii, H. Chem. Commun. 2009, 1909-1911. doi:10.1039/b823249k

13. Cho, E. J.; Senecal, T. D.; Kinzel, T.; Zhang, Y.; Watson, D. A.; Buchwald, S. L. Science 2010, 328, 1679-1681. doi:10.1126/science.1190524

14. Mizutani, K.; Yamazaki, T.; Kitazume, T. J. Chem. Soc., Chem. Commun. 1995, 51-52. doi:10.1039/C39950000051

15. Yamazaki, T.; Mizutani, K.; Kitazume, T. J. Org. Chem. 1995, 60, 6046-6056. doi:10.1021/jo00124a013

16. Konno, T.; Chae, J.; Kanda, M.; Nagai, G.; Tamura, K.; Ishihara, T.; Yamanaka, H. Tetrahedron 2003, 59, 7571-7580. doi:10.1016/S0040-4020(03)01199-2

17. Chen, Q.; Quu, X.-L.; Qing, F.-L. J. Fluorine Chem. 2007, 128, 1182-1186. doi:10.1016/j.jfluchem.2007.02.010

18. Jiang, Z.-X.; Qin, Y.-Y.; Qing, F.-L. J. Org. Chem. 2003, 68, 7544-7547. doi:10.1021/jo0344384

19. Xiong, Z.; Qiu, X.-L.; Huang, Y.; Qing, F.-L. J. Fluorine Chem. 2011, 132, 166-174. doi:10.1016/j.jluchem.2010.12.012

20. Hanamoto, T.; Hakoshima, Y.; Egashira, M. Tetrahedron Lett. 2004, 45, 7573-7576. doi:10.1016/j.tetlet.2004.08.118

21. Chen, X.-Y.; Quu, X.-L.; Qing, F.-L. Tetrahedron 2008, 64, 2301-2306. doi:10.1016/j.tet.2008.01.021

22. Yamazaki, T.; Ichige, T.; Kitazume, T. Org. Lett. 2004, 6, 4073-4076. doi:10.1021/ol048229x

23. Watanabe, Y.; Yamazaki, T. J. Org. Chem. 2011, 76, 1957-1960. doi:10.1021/jo102503s 
24. Yamazaki, Y.; Yamamoto, T.; Ichihara, R. J. Org. Chem. 2006, 71, 6251-6253. doi:10.1021/jo060909l

25. Yamazaki, T.; Kawasaki-Takasuka, T.; Furuta, A.; Sakamoto, S. Tetrahedron 2009, 65, 5945-5948. doi:10.1016/j.tet.2009.05.087

26. Konno, T.; Moriyasu, K.; Ishihara, T. Synthesis 2009, 1087-1094. doi:10.1055/s-0028-1087988

27. Brisdon, A. K.; Crossley, I. R.; Pritchard, R. G.; Sadiq, G.; Warren, J. E. Organometallics 2003, 22, 5534-5542. doi:10.1021/om034146t

28. Brisdon, A. K.; Crossley, I. R. Chem. Commun. 2002, 20, 2420-2421. doi:10.1039/b207979h

29. Yamazaki, T.; Takita, K.; Ishikawa, N. J. Fluorine Chem. 1985, 30, 357-363. doi:10.1016/S0022-1139(00)84971-4

30. Prakash, G. K. S.; Krishnan, H. S.; Jog, P. V.; Iyer, A. P.; Olah, G. A. Org. Lett. 2012, 14, 1146-1149. doi:10.1021/ol300076y

31. Omote, M.; Tanaka, M.; Ikeda, A.; Nomura, S.; Tarui, A.; Sato, K.; Ando, A. Org. Lett. 2012, 14, 2286-2289. doi:10.1021/ol300670n

32. Omote, M.; Tanaka, M.; Tanaka, M.; Ikeda, A.; Tarui, A.; Sato, K.; Ando, A. J. Org. Chem. 2013, 78, 6196-6201. doi:10.1021/jo400859s

33. Bizet, V.; Pannecoucke, X.; Renaud, J.-L.; Cahard, D. Angew. Chem., Int. Ed. 2012, 51, 6467-6470. doi:10.1002/anie.201200827

34. Bizet, V.; Pannecoucke, X.; Renaud, J.-L.; Cahard, D. J. Fluorine Chem. 2013, 152, 56-61. doi:10.1016/j.jfluchem.2013.01.004

35. Qing, F.; Gao, W. Chin. J. Org. Chem. 2000, 20, 764-768. http://sioc-journal.cn/Jwk_yjhx/EN/abstract/abstract333670.shtml

\section{License and Terms}

This is an Open Access article under the terms of the Creative Commons Attribution License

(http://creativecommons.org/licenses/by/2.0), which permits unrestricted use, distribution, and reproduction in any medium, provided the original work is properly cited.

The license is subject to the Beilstein Journal of Organic Chemistry terms and conditions:

(http://www.beilstein-journals.org/bjoc)

The definitive version of this article is the electronic one which can be found at: $\underline{\text { doi: } 10.3762 / \text { bjoc. } 9.279}$ 